\section{URINARY ANALYSIS AND DIAGNOSIS.}

By Louis HeitzmanN, M.D.

Baillière, Tindall \& Cox, 1934. p.p. 286. Price 22/6d.

In spite of its title, quite the most interesting and certainly the most original part (one third) of this book is that devoted to microscopical diagnosis. The author complains that urinary analysis, the most important of all laboratory examinations, as he calls it, is considered the simplest; and one is disposed to agree with him, with the proviso that it is rather in the wards than in the laboratory that such examinations are considered to be simple. He goes on to say that these examinations are in consequence of slight aid to the physician and are frequently misleading. The trouble is, of course, that a complete overhaul of the urine (including many matters, such as the light it can throw on the metabolism, not referred to by the author) is somewhat of an undertaking and would require a special annexe to the laboratory, wherein under the eye of the pathologist but without being in his way, the houseman in his spare time (if any) could disport himself and learn a good deal.

An interesting method (that of Kirkpatrick and Kling) for the determination of the specific gravity on a few drops of urine is described at p. 25. The author's statement (p. 42) that urœrythrin is of no practical importance belies his own thesis, viz., that the urine ought to be more carefully examined. On more than one occasion the reviewer has been told that this pigment was obviously due to blood. Nor are matters mended by the adoption of pre-microscopic tests, such as the alleged chemical tests for blood and pus. One would, on occasion, go farther even than the author, who requires the cytology done with medium power and cover slip, and insist that traces of blood be looked for in a Leishman smear.

The author concentrates on microscopical diagnosis and claims that close attention to the various epithelial elements encountered in the urine is of great diagnostic importance, illustrating his remarks with numerous drawings, which, however, are rather crowded and hardly "photographic" enough. He gives the wise counsel that the learner should familiarise himself with the various kinds of epithelia by the careful microscopic examination of urine from known cases of pyelitis, cystitis, nephritis and other affections of the genito-urinary tract.

\section{PSYCHOPATHOLOGY : A SURVEY OF MODERN APPROACHES.}

By J. ERnest Nicole, with foreword by W. H. B. Stoddart. Second Edition. London: Baillière, Tindall \& Cox. 1934. Pp. xv. + 283. 12s. 6d.

The appearance of a second edition of Dr. Nicole's Psychopathology is evidence of his success in meeting a need. Many additions have been made and have increased the size of the book by nearly 50 per cent. The aim of the book is to give briefly the views of the different schools of modern psychopathology and to show their relationships to one another, and it has been achieved, for into 164 pages there have been crowded condensed accounts of the theories of Prince, Freud, Adler, Jung, Rivers, Watson, Kempf, Berman, Kretschmer, and of much of the recent work on the biochemical, ethnological and sociological approaches to psychopathology.

Unfortunately, the book is somewhat lopsided, for while only 164 pages have been devoted to its main theme, 78 pages of appendices have been added; these consist of reprints of three papers on "The Concept of the Ego in Psychiatry," "Type Psychology with special reference to Jung," and "Psychopathology and the Herd Instinct." One can sympathise with the author, for describing the theories and investigations of others is a much duller task than describing one's own researches; still, it would have been preferable if the author had reprinted these appendices elsewhere and devoted the extra 78 pages and his obvious erudition, for he knows his subject-matter : well, to a more detailed account of the trends of thought which he set out to describe.

An interesting feature of the book is the attempt to avoid a narrowly medical point of view by bringing psychopathology into relation with psychology, ethnology and other fields of study. A very useful bibliography is added of books written in or translated into English since 1900. 